\title{
Bizarreness and recall
}

\author{
STEVEN D. COX and KEITH A. WOLLEN \\ Washington State University, Pullman, Washington 99164
}

\begin{abstract}
Although memory experts have long advocated the use of bizarre imagery to aid memory, most research has failed to find bizarreness to be effective. Recently, bizarreness has been shown to be effective, but those experiments involved mixed lists in which each subject had both bizarre and nonbizarre materials. The goal of the present research was to use the same materials but in an unmixed-list design in which each subject had only bizarre or only nonbizarre sentences. Contrary to previous research, there were no significant differences between bizarre and nonbizarre conditions in terms of the number of individual words recalled, and bizarreness produced significantly lower recall of complete sentences. It was concluded that bizarreness is effective only when bizarre and nonbizarre materials are provided by the experimenter in a mixed-list situation.
\end{abstract}

For centuries, so-called memory experts have stressed that associations between objects are most easily remembered if those objects are depicted in a mental image. However, not just any mental image will do. According to these experts, the image will be effective only if it is bizarre. The importance of bizarreness is illustrated by the following passage describing how to associate "paper" and "carpet." "The association must be as ridiculous as possible.... A sheet of paper lying on a carpet would not make a good association. It is too logical! Your mental picture must be ridiculous or illogical ... if your association is a logical one, you will not remember it" (Lorayne, 1957, p. 40).

Although the advice of memory experts seems reasonable, it has been extremely difficult to find empirical support for it. Several experimenters have found bizarre images to be no more effective than nonbizarre ones (e.g., Senter \& Hoffman, 1976; Wollen, Weber, \& Lowry, 1972). These people used unmixed lists in which subjects had only nonbizarre materials. Recently, several experimenters have used mixed-list designs and reported evidence that bizarreness is effective (Merry, 1980; Merry \& Graham, 1978; Webber \& Marshall, 1978). In the latter group of studies, subjects were given both bizarre and nonbizarre interactions in the form of sentences or line drawings. The novelty of the bizarre materials might well result in subjects spending more time learning the bizarre pairings at the expense of the nonbizarre ones. If so, the superiority of bizarre materials should disappear if subjects are given unmixed lists that contain only bizarre or only nonbizarre items. The goal of the following experiment was to examine this possibility using the same sentences that were used in Merry's experiments. We predicted that the superiority of bizarre materials would disappear in mixed lists.

Requests for reprints should be sent to Keith A. Wollen, Department of Psychology, Washington State University, Pullman, Washington 99164.

\section{METHOD}

\section{Materials and Subjects}

The materials, which are shown in Table 1, were derived from those used by Merry and Graham (1978). Since an unmixedlist design was used, each subject had either 12 bizarre sentences or 12 nonbizarre sentences. The subjects were 25 males and 28 females who were run in small groups of about 13 .

\section{Procedure}

There were three stages. In Stage 1 , the 12 sentences were read at a rate of 1 sentence every $8 \mathrm{sec}$. An incidental learning task similar to Merry's (1980) was used. It involved asking subjects to form a mental image of the events or relationships described in each sentence and then to rate that image on a 5 -point scale of bizarreness. The scale ranged from a rating of 1 for an ordinary image (something that one might see in real life) to a 5 for an unlikely image (something ridiculous that would not be seen in real life). Examples were given of a rating of 1 ("The mouse ran across the floor") and a rating of 5 ("The elephant played a guitar"). All subjects were told there was no need to remember the sentences.

Stage 2 was a distractor task. Immediately after the rating sheets were collected, a sheet containing a typewritten passage was passed out. Subjects were given $1 \mathrm{~min}$ to count the number of times the letter "e" appeared. This task was described as a measure of speed and accuracy. The experimenter indicated when the minute was over, and subjects marked where they had stopped and how many "es" they had counted. These sheets were then collected.

Table 1

Materials

The policeman drove the car (ate the hay).

The soldier waved the flag (licked the kitten).

The fish lived in a pond (spoke on the telephone).

The man smoked a cigar (pecked the worm).

The dog lived in the kennel (wrote on the blackboard).

The teacher wrote on the blackboard (lived in the kennel).

The doctor spoke on the telephone (lived in a pond).

The hen pecked the worm (smoked a cigar).

The horse ate the hay (drove the car).

The monkey climbed up the tree (read the newspaper)

The cat licked the kitten (waved the flag).

The judge read the newspaper (climbed up the tree).

Note-Bizarre sentence endings are in parentheses. 
Stage 3 began with the distribution of the recall sheets. Each sheet had 12 lines. Subjects were asked to write as many of the sentences as they could, one sentence per line, in any order they wished. The subjects were asked to write the sentences as close to the original wording as they could, but they were encouraged to write whatever part of a sentence they could remember, even if it was only one or two words. The subjects were allowed whatever time they needed to complete this task.

\section{RESULTS AND DISCUSSION}

A check was made to see whether the subjects' ratings of the bizarreness of the sentences corresponded to the classification given them by the experimenters. In general, the subjects appeared to agree with our designations. A mean rating for the 12 sentences was determined for each subject. The means of these values was 1.39 for nonbizarre sentences and 4.41 for bizarre ones.

Each sentence has three main words, the first noun (N1), the verb (V), and the second noun (N2). The mean number of times each of these was recalled correctly, irrespective of being matched correctly with the other sentence components, is shown in the first three rows of Table 2 .

None of these differences approached significance. Thus, the unmixed-list design used herein did not produce the superiority for bizarre sentences found by the mixed-list procedure used by Merry (Merry, 1980; Merry \& Graham, 1978). An interpretation of this difference in results is that subjects spend more time rehearsing the bizarre sentences, possibly because they are more interesting than nonbizarre sentences. However, if nonbizarre sentences are all subjects have, they would probably devote all of their time to them, thereby eliminating the superiority of bizarre-sentence recall.

The preceding interpretation would have to apply only to situations in which the experimenter actually presents bizarre vs. nonbizarre materials. The reason for this is that no superiority for bizarreness has been obtained when word pairs are presented and subjects are asked to form their own bizarre or nonbizarre images (Nappe \& Wollen, 1973). The latter finding may not be as contradictory as it might seem at first. It could be that subjects devote equal attention to bizarre and nonbizarre images when asked to generate their own images and yet spend more time on bizarre materials than on nonbizarre ones when these materials are provided by the experimenter. If more time is spent on bizarre sentences, it might be expected that they would be learned better and hence recalled better. In the study reported herein, such a "contrast" effect would not have been operative.

Most memory experts emphasize the use of bizarre imagery for the association of words. Hence, the data most relevant for tests of the advice of these experts is the extent to which $\mathrm{N} 1, \mathrm{~V}$, and $\mathrm{N} 2$ were appropriately matched. This was examined by determining the number of times that $\mathrm{N} 1, \mathrm{~V}$, and $\mathrm{N} 2$ were matched correctly; the resulting means are shown in the last row of Table 2. As can be seen, rather than bizarre sentences producing
Table 2

Mean Number Correct

\begin{tabular}{|c|c|c|}
\hline \multirow{2}{*}{$\begin{array}{c}\text { Unit } \\
\text { Recalled }\end{array}$} & \multicolumn{2}{|c|}{ Type of Sentence } \\
\hline & Bizarre & Nonbizarre \\
\hline $\begin{array}{l}\text { Noun } 1 \\
\text { Verb } \\
\text { Noun } 2 \\
\text { Noun } 1+\text { Verb + Noun } 2\end{array}$ & $\begin{array}{l}6.46 \\
6.79 \\
6.11 \\
4.96\end{array}$ & $\begin{array}{l}6.64 \\
6.68 \\
6.68 \\
6.56\end{array}$ \\
\hline
\end{tabular}

greater recall, they produced significantly less $[t(51)=$ $3.64, \mathrm{p}<.01$ ]. If $\mathrm{V}$ is ignored and only $\mathrm{N} 1$ and $\mathrm{N} 2$ are examined for the number of correct pairings, the result is nearly identical; the resulting means are 5.04 for bizarre and 6.56 for nonbizarre $(t=3.43)$.

The major difference between the results for bizarre and nonbizarre conditions is that if subjects recalled part of a nonbizarre sentence, they generally recalled the entire sentence. This is verified by examination of the conditional probabilities of recalling $\mathrm{V}$ given $\mathrm{N} 1$ (.99), N2 given V (1.00), and N2 given N1 (.99). On the other hand, subjects given bizarre sentences frequently recalled part of a sentence without the rest of it. This also was shown in the conditional probabilities of $\mathrm{V}: \mathrm{N} 1=.87, \mathrm{~N} 2: \mathrm{V}=.88$, and $\mathrm{N} 2: \mathrm{N} 1=.78$.

The reason that nonbizarre sentences produced higher conditional probabilities may be that $\mathrm{N} 1, \mathrm{~V}$, and $\mathrm{N} 2$ are more associatively related in nonbizarre than in bizarre sentences. As can be seen in Table 1, there appears to be more relationship among the words in nonbizarre sentences. For example, a man can and often does smoke a cigar, whereas a hen never does. Thus, nonbizarre materials probably have greater initial associative strength. If so, the advice of memory experts to use bizarre materials is especially puzzling. In general, it appears that bizarreness will be effective only when a mixed-list design is used, and then only when the experimenter provides subjects with the bizarre or nonbizarre materials.

\section{REFERENCES}

LoRAYNe, H. How to develop a super-power memory. New York: Fell, 1957.

Merry, R. Image bizarreness in incidental learning. Psychological Reports, 1980, 46, 427-430.

MerRy, R., \& Graham, N. C. Imagery bizarreness in children's recall of sentences. British Journal of Psychology, 1978, 69, 315-321.

Nappe, G. W., \& Wollen, K. A. Effects of instructions to form common and bizarre mental images on retention. Journal of Experimental Psychology, 1973, 100, 6-8.

Senter, R. J., \& Hoffman, R. R. Bizarreness as a nonessential variable in mnemonic imagery: A confirmation. Bulletin of the Psychonomic Society, 1976, 7, 163-164.

Webber, S. M., \& Marshall, P. H. Bizarreness effects in imagery as a function of processing level and delay. Journal of Mental Imagery, 1978, 2, 291-300.

Wollen, K. A., Weber, A., \& LoWry, D. H. Bizarreness versus interaction of mental images as determinants of learning. Cognitive Psychology, 1972, 3, 518-523.

(Received for publication September 5, 1981.) 